Pacific Journal of Mathematics

ON COMMON FIXED POINT SETS OF COMMUTATIVE 


\section{ON COMMON FIXED POINT SETS OF COMMUTATIVE MAPPINGS}

\section{TECK-CheONG LIM}

Let $C$ be a compact convex subset of a locally convex topological vector space $X$. Anzai and Ishikawa recently proved that if $T_{1}, \cdots, T_{n}$ is a finite commutative family of continuous affine self-mappings of $C$, then $F\left(\sum_{i=1}^{n} \lambda_{i} T_{i}\right)=$ $\bigcap_{i=1}^{n} F\left(T_{i}\right)$ for every $\lambda_{i}$ such that $0<\lambda_{i}<1$ and $\sum_{i=1}^{n} \lambda_{i}=1$, where $F(T)$ denotes the fixed point set of $T$. It is natural to question whether the conclusion of their theorem is dependent on the topological properties of $X, C$ and $T_{i}$-in this case, the linear topology, the compactness and the continuity. We shall see that this is not; the theorem can be formulated in an algebraic context.

Our theorem, when applied to Hausdorff topological vector spaces, yields a better version of Anzai-Ishikawa's theorem (see Corollary 2).

Definition 1. A subset $B$ of a real vector space is said to be (algebraically) bounded if $\bigcap_{\varepsilon>0} \varepsilon(C-C)=\{0\}$, where $C=\mathrm{C}_{0}(B)$, the convex hull of $B$.

Every bounded convex subset of a Hausdorff topological vector space is algebraically bounded. Every bounded subset of a locally convex Hausdorff topological vector space is algebraically bounded.

THEOREM 1. Let $C$ be a convex subset of a real vector space $X$ and $T_{1}, \cdots, T_{n}$ a finite commutative family of affine self-mappings of $C$. If the set $D=\left\{T_{1}^{m_{1}} T_{2}^{m_{2}} \cdots T_{n}^{m_{n}} x: 0 \leqq m_{i}<\infty, i=1, \cdots, n\right\}$ is bounded for each $x \in C$, then $F\left(\sum_{i=1}^{n} \lambda_{i} T_{i}\right)=\bigcap_{i=1}^{n} F\left(T_{i}\right)$ for every $0<$ $\lambda_{i}<1$ with $\sum_{i=1}^{n} \lambda_{i}=1$.

LEMMA 1. Let $x_{n}$ be a sequence in a Banach space such that $x_{n} \rightarrow x$. Then the sequence $y_{n}$ defined by

$$
y_{n}=\left(1 / 2^{n}\right)\left(x_{0}+{ }_{n} C_{1} x_{1}+\cdots+{ }_{n} C_{i} x_{i}+\cdots+x_{n}\right)
$$

converges to $x$.

Proof. For an arbitrary $\varepsilon>0$, choose $m$ such that $\left\|x_{i}-x\right\|<$ $\varepsilon / 2$ for $i \geqq m$. Choose $N \geqq m$ such that

$$
1 / 2^{n}\left(1+{ }_{n} C_{1}+\cdots+{ }_{n} C_{m-1}\right)<\varepsilon /(2 D)
$$

for all $n \geqq N$, where $D$ is a number such that $\left\|x_{i}-x\right\| \leqq D$ for all $i \geqq 0$. Then 


$$
\begin{aligned}
\| y_{n} & -x \| \\
& =\left\|\left(1 / 2^{n}\right)\left(x_{0}-x+{ }_{n} C_{1}\left(x_{1}-x\right)+\cdots+{ }_{n} C_{m-1}\left(x_{m-1}-x\right)+\cdots+x_{n}-x\right)\right\| \\
& \leqq\left(1 / 2^{n}\right)\left(1+{ }_{n} C_{1}+\cdots+{ }_{n} C_{m-1}\right) D+(\varepsilon / 2)\left(1 / 2^{n}\right)\left({ }_{n} C_{m}+\cdots+1\right) \\
& <\varepsilon
\end{aligned}
$$

for all $n \geqq N$.

REMARK 1. The above lemma is also a consequence on SilvermanToeplitz's theorem on regular method of summability.

Proof of Theorem 1. We may assume that $n=2$. The inclusion $\bigcap_{1}^{n} F\left(T_{i}\right) \subset F\left(\sum_{1}^{n} \lambda_{i} T_{i}\right)$ is obvious. Let $A=\lambda_{1} I+\lambda_{2} T_{1}, B=\lambda_{2} I+\lambda_{1} T_{2}$ and $T=(1 / 2)(A+B)$. Then $T=(1 / 2)\left(I+\lambda_{1} T_{1}+\lambda_{2} T_{2}\right)$. Moreover, $F(T)=F\left(\lambda_{1} T_{1}+\lambda_{2} T_{2}\right), F(A)=F\left(T_{1}\right)$ and $F(B)=F\left(T_{2}\right)$. Let $x \in F\left(\lambda_{1} T_{1}+\right.$ $\left.\lambda_{2} T_{2}\right)=F(T)$. For every $n$, we have

$$
\begin{aligned}
x & =\left(\frac{A+B}{2}\right)^{n} x \\
& =\frac{1}{2^{n}}\left(A^{n} x+{ }_{n} C_{1} A^{n-1} B x+\cdots+{ }_{n} C_{i} A^{n-i} B^{i} x+\cdots+B^{n} x\right)
\end{aligned}
$$

and

(2) $T_{1} x=\frac{1}{2^{n}}\left(T_{1} A^{n} x+{ }_{n} C_{1} T_{1} A^{n-1} B x+\cdots+{ }_{n} C_{i} T_{1} A^{n-i} B^{i} x+\cdots+T_{1} B^{n} x\right)$,

where we make use of the commutativity of $A$ and $B$ and the affine property of $T_{1}$.

Following Anzai-Ishikawa's computation [1], we have

$$
\begin{aligned}
A^{m} y-T_{1} A^{m} y & =\sum_{i=0}^{m}{ }_{m} C_{i} \lambda_{1}^{m-i} \lambda_{2}^{i} T_{1}^{i} y-\sum_{i=1}^{m+1}{ }_{m} C_{i-1} \lambda_{1}^{m-i+1} \lambda_{2}^{i-1} T_{1}^{i} y \\
& =\sum_{i=0}^{m+1}\left({ }_{m} C_{i} \lambda_{1}^{m-i} \lambda_{2}^{i}-{ }_{m} C_{i-1} \lambda_{1}^{m-i+1} \lambda_{2}^{i-1}\right) T_{1}^{i} y,{ }_{m} C_{-1}={ }_{m} C_{m+1}=0 \\
& =\sum_{i=0}^{m_{0}} \mu_{i} T_{1}^{i} y-\sum_{i=m_{0}+1}^{m+1}\left(-\mu_{i}\right) T_{1}^{i} y \\
& =a_{m}\left(\sum_{i=0}^{m_{0}} \alpha_{i} T_{1}^{i} y-\sum_{i=m_{0}+1}^{m+1} \beta_{i} T_{1}^{i} y\right) .
\end{aligned}
$$

Here, $m_{0}$ is the largest integer less than or equal to $\lambda_{2}(m+1)$;

$$
\mu_{i}={ }_{m} C_{i} \lambda_{1}^{m-i} \lambda_{2}^{i}-{ }_{m} C_{i-1} \lambda_{1}^{m-i+1} \lambda_{2}^{i-1},
$$

$\mu_{i} \geqq 0$ for $0 \leqq i \leqq m_{0}$ and $<0$ for $m_{0}+1 \leqq i \leqq m+1$;

$$
a_{m}=\sum_{i=0}^{m_{0}} \mu_{i}=\sum_{i=m_{0}+1}^{m+1}\left(-\mu_{i}\right)={ }_{m} C_{m_{0}} \lambda_{1}^{m-m_{0}} \lambda_{2}^{m_{0}} \longrightarrow 0
$$


as $m \rightarrow \infty ; \alpha_{i}=\mu_{i} / a_{m} \geqq 0$ for $0 \leqq i \leqq m_{0}, \beta_{i}=-\mu_{i} / a_{m} \geqq 0$ for $m_{0}+$ $1 \leqq i \leqq m+1, \sum_{i=0}^{m_{0}} \alpha_{i}=1$ and $\sum_{i=m_{0}+1}^{m+1} \beta_{i}=1$.

Let $E=C_{0}(D)$. By the convexity of $E, A^{m} y-T_{1} A^{m} y \in a_{m}(E-E)$ provided $T_{1}^{i} y \in E$ for $i=0, \cdots, m+1$.

Since $T_{1}$ and $T_{2}$ are affine, $T_{1}^{i} A^{k} B^{j} x \in E$ for $j, k=0, \cdots, n ; i=$ $0,1, \cdots$. It follows from (1) and (2) that

$x-T_{1} x$

$$
\begin{aligned}
& =\frac{1}{2^{n}}\left(\left(A^{n} x-T_{1} A^{n} x\right)+n C_{1}\left(A^{n-1} B x-T_{1} A^{n-1} B x\right)+\cdots+\left(B^{n} x-T_{1} B^{n} x\right)\right) \\
& \in \frac{1}{2^{n}}\left(a_{n}(E-E)+{ }_{n} C_{1} a_{n-1}(E-E)+\cdots+{ }_{n} C_{n-1} a_{1}(E-E)+a_{0}(E-E)\right) \\
& \subseteq \frac{1}{2^{n}}\left(a_{0}+n C_{1} a_{1}+\cdots+{ }_{n} C_{i} a_{i}+\cdots+a_{n}\right)(E-E),
\end{aligned}
$$

the last inclusion being a consequence of the convexity of $E-E$.

Since $E-E$ is convex and $0 \in E-E$, we have $\varepsilon_{1}(E-E) \leqq$ $\varepsilon_{2}(E-E)$ if $\varepsilon_{1}<\varepsilon_{2}$. Hence by Lemma 1 and the boundedness of $E$, $\bigcap_{1}^{n} A(n)(E-E)=\{0\}$ where

$$
A(n)=\frac{1}{2^{n}}\left(a_{0}+{ }_{n} C_{1} a_{1}+\cdots+{ }_{n} C_{i} a_{i}+\cdots+a_{n}\right)
$$

It follows that $x=T_{1} x$. Similarly $x=T_{2} x$. This completes the proof.

COROLlary 1. Let $C$ be a bounded convex subset of a vector space and $T_{1}, \cdots, T_{n}$ a finite commutative family of affine mappings of $C$. Then $F\left(\sum_{i=1}^{n} \lambda_{i} T_{i}\right)=\bigcap_{i=1}^{n} F\left(T_{i}\right)$ for all positive numbers $\lambda_{i}$, $i=1, \cdots, n$ such that $\sum_{i=1}^{n} \lambda_{i}=1$.

CoROLlary 2. Let $C$ be a convex bounded (in the usual sense) subset of a Hausdorff topological vector space and $T_{1}, \cdots, T_{n}$ a finite commutative family of affine mappings of $C$. Then $F\left(\sum_{i}^{n} \lambda_{i} T_{i}\right)=$ $\bigcap_{1}^{n} F\left(T_{i}\right)$ for all positive numbers $\lambda_{i}, i=1, \cdots, n$ such that $\sum_{1}^{n} \lambda_{i}=1$.

REMARK 2. We note that the boundedness condition cannot be removed. The mappings $T_{1} x=x+a, T_{2} x=x-a, a \neq 0$ defined on $R^{1}$ are commutative and affine, with $F\left(T_{1}\right)=F\left(T_{2}\right)=\phi$ and $F\left((1 / 2) T_{1}+(1 / 2) T_{2}\right)=R^{1}$.

Corollary 3. Let $C, T_{i}, i=1, \cdots, n$ be defined as in Corollary 2. Assume that $T_{1}^{p} \cdots T_{n}^{p}=T_{1} \cdots T_{n}$ for some $p \geqq 2$ and that for each $x \in C$ and each $i=1, \cdots, n$, the set

$$
A_{i} x=\left\{T_{T_{1}}^{m_{1}} \cdots \hat{T}_{i}^{m_{i}} \cdots T_{n}^{m_{n}} X: 0 \leqq m_{j}<\infty, j=1, \cdots, n\right\}
$$


is bounded, where $\wedge$ indicates that $T_{i}^{m_{i}}$ is missing. Then $F\left(\sum_{1}^{n} \lambda_{i} T_{i}\right)=$ $\bigcap_{1}^{n} F\left(T_{i}\right)$ for all positive numbers $\lambda_{i}, i=1, \cdots, n$ such that $\sum_{1}^{n} \lambda_{i}=1$.

Proof. If $m_{i}, i=1, \cdots, n$ are $n$ natural numbers and $m_{j}=$ $\min \left\{m_{i}, i=1, \cdots, n\right\}$, then

$$
\begin{aligned}
T_{1}^{m_{1}} \cdots T_{n}^{m_{n}} X & =T_{1}^{m_{1}-m_{j}} \cdots \widehat{T}_{j}^{m_{j}-m_{j}} \cdots T_{n}^{m_{n}-m_{j}} T_{1}^{m_{j}} \cdots T_{n}^{m_{j}} x \\
& =T_{1}^{m_{1}-m_{j}} \cdots T_{n}^{m_{n}-m_{j}} T_{1}^{k} \cdots T_{n}^{k} x \in A_{j}\left(T_{1}^{k} \cdots T_{n}^{k} x\right)
\end{aligned}
$$

where $k$ is an integer satisfying $0 \leqq k<p$. It follows that

$$
\begin{aligned}
A x & =\left\{T_{1}^{m_{1}} \cdots T_{n}^{m_{n}} x: 0 \leqq m_{i}<\infty, i=1, \cdots, n\right\} \\
& =\bigcup\left\{A_{i}\left(T_{1}^{k} \cdots T_{n}^{k} x\right): i=1, \cdots, n, k=0, \cdots, p-1\right\} .
\end{aligned}
$$

Hence $A x$, being a finite union of bounded sets is bounded.

The special case when $n=2$ and $p=2$ can be given a simple direct proof. We shall illustrate it for the case $\lambda_{1}=\lambda_{2}=1 / 2$. First we prove:

LEMMA 2. For each $n \geqq 1$, there exists rational numbers (depending on $n$ and not necessarily nonnegative) $\lambda_{1}, \cdots, \lambda_{[n / 2]}$ such that

$$
\lambda_{1}+\cdots+\lambda_{[n / 2]}=1-\left(1 / 2^{n-1}\right)
$$

and such that the equation

$$
\begin{aligned}
D^{n}= & \left(1 / 2^{n-1}\right)\left(\frac{A^{n}+B^{n}}{2}\right)+\lambda_{1} A B D^{n-2}+\cdots+\lambda_{i} A^{i} B^{i} D^{n-2 i}+\cdots \\
& +\lambda_{[n / 2]} A^{[n / 2]} B^{[n / 2]} D^{n-2[n / 2]}
\end{aligned}
$$

is valid for any two commutative affine mappings $A, B$ defined on a convex set, where $D=1 / 2(A+B) . \quad([m]$ denotes the largest integer $\leqq m$.

Proof. If such rational numbers $\lambda_{i}$ exist for a fixed $n$, then by putting $A=B=I$, we see that

$$
\lambda_{1}+\cdots+\lambda_{[n / 2]}=1-\left(1 / 2^{n-1}\right) .
$$

We shall prove by induction on $n$. For $n=2, \lambda_{1}=1 / 2$. Assume that the lemma is true for $m \leqq n$. Then

$$
\begin{aligned}
D^{n+1}= & D^{n} D=\left(1 / 2^{n}\right)\left(\frac{A^{n+1}+B^{n+1}}{2}\right)+\frac{1}{2}\left(1 / 2^{n-2}\right)\left(\frac{A^{n-1}+B^{n-1}}{2}\right) A B \\
& +\lambda_{1} A B D^{n-1}+\cdots+\lambda_{[n / 2]} A^{[n / 2]} B^{[n / 2]} D^{n-2[n / 2]+1} .
\end{aligned}
$$


Making use of the induction hypothesis for $m=n-1$, substitue

$$
\begin{aligned}
\left(1 / 2^{n-2}\right)\left(\frac{A^{n+1}+B^{n+1}}{2}\right)= & D^{n-1}-\mu_{1} A B D^{(n+1)-4}-\cdots \\
& -\mu_{[(n-1) / 2]} A^{[(n-1 / 2]} B^{[(n-1 / 2]} D^{n-1-2[(n-1) / 2]}
\end{aligned}
$$

into (4). The proof will be then complete by collecting similar terms and making use of $[(n-1) / 2]+1=[(n+1) / 2]$ and $[(n+1) / 2]-[n / 2]=0$ or 1.

Corollary 4. Let $C$ be defined as in Theorem 1 and $A, B$ be two commutative affine self-mappings of $C$ such that $A^{2} B^{2}=A B$ and such that the sets $\left\{A^{n} x: n=0,1,2, \cdots\right\}$ and $\left\{B^{n} x: n=0,1,2, \cdots\right\}$ are bounded for each $x \in C$. Then $F((1 / 2) A+(1 / 2) B)=F(A) \cap F(B)$.

Proof. Let $x \in F((1 / 2) A+(1 / 2) B)$. Using Lemma 2 and the condition $A^{2} B^{2}=A B$, we have

$$
x=\left(\frac{A+B}{2}\right)^{n} x=\left(1 / 2^{n-1}\right)\left(\frac{A^{n} x+B^{n} x}{2}\right)+\left(1-\frac{1}{2^{n-1}}\right) A B x .
$$

Thus,

$$
x-A B x=\frac{1}{2^{n-1}}\left(\frac{A^{n} x+B^{n} x}{2}-A B x\right) .
$$

By the boundedness condition, we see that $A B x=x$. By (3) for $n=2$, we have $x=\left(A^{2} x+B^{2} x\right) / 2$. By applying $A$ to $x=(1 / 2) A x+$ $(1 / 2) B x$ we have $A x=(1 / 2) A^{2} x+(1 / 2) x$ and hence $A^{2} x-x=2(A x-x)$. Thus by repeatedly replacing $A, B$ by $A^{2}$ and $B^{2}$ in the above argument, we obtain $A^{2 n} x-x=2^{n}(A x-x)$. This contradicts the boundedness of $\left\{A^{n} x: n=0,1,2, \cdots\right\}$ unless $A x=x$. Similarly $B x=x$, completing the proof.

\section{REFERENCES}

1. K. Anzai and S. Ishikawa, On common fixed points for several continuous affine mappings, Pacific J. Math., 72 (1977), 1-4.

Received March 3, 1978.

61-C, Lorong Kumara,

SINGAPORE 27

Present address: Department of Mathematics The University of Chicago

Chicago, IL 60637 



\section{PACIFIC JOURNAL OF MATHEMATICS}

\section{EDITORS}

RICHARD ARENS (Managing Editor)

University of California

Los Angeles, CA 90024

Charles W. Curtis

University of Oregon

Eugene, OR 97403

C. C. MOORE

University of California

Berkeley, CA 94720
J. DUGUNDJI

Department of Mathematics

University of Southern California

Los Angeles, CA 90007

R. FINN and J. MILGRAM

Stanford University

Stanford, CA 94305

\section{ASSOCIATE EDITORS}

\section{E. F. BeCKENBACH}

B. H. NeumanN

F. WOLF

K. YoSHIDA

\section{SUPPORTING INSTITUTIONS}

\author{
UNIVERSITY OF SOUTHERN CALIFORNIA \\ STANFORD UNIVERSITY \\ UNIVERSITY OF HAWAII \\ UNIVERSITY OF TOKYO \\ UNIVERSITY OF UTAH \\ WASHINGTON STATE UNIVERSITY \\ UNIVERSITY OF WASHINGTON
}

The Supporting Institutions listed above contribute to the cost of publication of this Journal, but they are not owners or publishers and have no responsibility for its content or policies.

Mathematical papers intended for publication in the Pacific Journal of Mathematics should be in typed form or offset-reproduced, (not dittoed), double spaced with large margins. Please do not use built up fractions in the text of the manuscript. However, you may use them in the displayed equations. Underline Greek letters in red, German in green, and script in blue. The first paragraph or two must be capable of being used separately as a synopsis of the entire paper. Items of the bibliography should not be cited there unless absolutely necessary, in which case they must be identified by author and journal, rather than by item number. Manuscripts, in triplicate, may be sent to any one of the editors. Please classify according to the scheme of Math. Reviews, Index to Vol. 39. All other communications should be addressed to the managing editor, or Elaine Barth, University of California, Los Angeles, California, 90024.

50 reprints to each author are provided free for each article, only if page charges have been substantially paid. Additional copies may be obtained at cost in multiples of 50 .

The Pacific Journal of Mathematics is issued monthly as of January 1966. Regular subscription rate: $\$ 72.00$ a year (6 Vols., 12 issues). Special rate: $\$ 36.00$ a year to individual members of supporting institutions.

Subscriptions, orders for numbers issued in the last three calendar years, and changes of address should be sent to Pacific Journal of Mathematics, P.O. Box 969, Carmel Valley, CA 93924, U.S.A. Older back numbers obtainable from Kraus Periodicals Co., Route 100, Millwood, NY 10546.

PUBLISHED BY PACIFIC JOURNAL OF MATHEMATICS, A NON-PROFIT CORPORATION

Printed at Kokusai Bunken Insatsusha (International Academic Printing Co., Ltd.). 8-8, 3-chome, Takadanobaba, Shinjuku-ku, Tokyo 160, Japan. 


\section{Pacific Journal of Mathematics}

\section{Vol. 80, No. $2 \quad$ October, 1979}

K. Adachi, On the multiplicative Cousin problems for $N^{p}(D) \ldots \ldots \ldots \ldots 297$

Howard Banilower, Isomorphisms and simultaneous extensions in $C(S) \ldots 305$

B. R. Bhonsle and R. A. Prabhu, An inversion formula for a distributional

finite-Hankel-Laplace transformation ................... 313

Douglas S. Bridges, Connectivity properties of metric spaces.......... 325

John Patton Burgess, A selection theorem for group actions ........... 333

Carl Claudius Cowen, Commutants and the operator equations

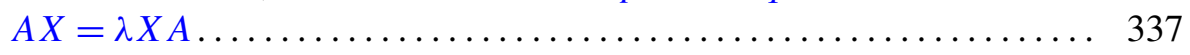

Thomas Curtis Craven, Characterizing reduced Witt rings. II .......... 341

J. Csima, Embedding partial idempotent d-ary quasigroups ............ 351

Sheldon Davis, A cushioning-type weak covering property ............ 359

Micheal Neal Dyer, Nonminimal roots in homotopy trees ............. 371

John Erik Fornaess, Plurisubharmonic defining functions ........... 381

John Fuelberth and James J. Kuzmanovich, On the structure of finitely

generated splitting rings .......................... 389

Irving Leonard Glicksberg, Boundary continuity of some holomorphic

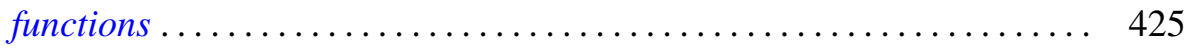

Frank Harary and Robert William Robinson, Generalized Ramsey theory.

IX. Isomorphic factorizations. IV. Isomorphic Ramsey numbers .......

Frank Harary and Allen John Carl Schwenk, The spectral approach to determining the number of walks in a graph...........

David Kent Harrison, Double coset and orbit spaces ..... . .

Shiro Ishikawa, Common fixed points and iteration of commuting

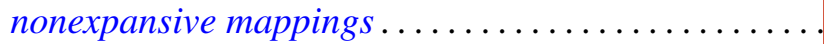

Philip G. Laird, On characterizations of exponential polynomials ........ 503

Y. C. Lee, A Witt's theorem for unimodular lattices ...........

Teck Cheong Lim, On common fixed point sets of commutative

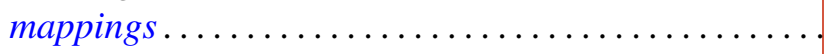

R. S. Pathak, On the Meijer transform of generalized functions ...

T. S. Ravisankar and U. S. Shukla, Structure of $\Gamma$-rings . . .

Olaf von Grudzinski, Examples of solvable and nonsolvable convolution

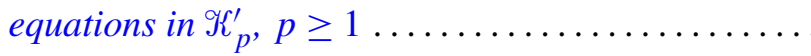

